\title{
Psicoterapia de casal na pós-modernidade: rupturas e possibilidades
}

\section{Couple psychotherapy in post-modernity: changes and possibilities}

\author{
Orestes DINIZ NETO' \\ Terezinha FÉRES-CARNEIRO²
}

\begin{abstract}
Resumo
O objetivo deste trabalho foi abordar a crise da conjugalidade na pós-modernidade e indicar novas possibilidades psicoterapêuticas. São traçadas as características do movimento pós-moderno, ressaltando suas relações com a produção de novas formas de subjetividade e de conjugalidade. O impacto na cultura brasileira é revisto. As mudanças da conjugalidade são compreendidas em suas implicações para a prática da psicoterapia de casal em um enfoque construcionista. Aspectos das rupturas na epistemologia do "si-mesmo" são apontados como possibilidades de novas direções psicoterapêuticas.
\end{abstract}

Palavras-chave: psicoterapia de grupo; pós-modernidade; relações conjugais; subjetivação.

\begin{abstract}
The purpose of this paper was to analyze the post-modern marriage crisis and the new psychotherapeutic possibilities. The post-modern characteristics are pointed in connection to the development of new marriage and subjective organizations. The effects on the Brazilian culture are summarized, and the conjugality changes implications are relevant to couple psychotherapy in a systemic approach. The "self" epistemological changes are pointed as new psychotherapeutic possible directions.
\end{abstract}

Key words: group psychotherapy; post modernism; marital relations; subjectivity.

O objetivo deste trabalho foi realizar um estudo das relações de produção de subjetividade nas relações conjugais na pós-modernidade, apontando suas implicações para uma prática de psicoterapia de casal.

Na metade do século XX e início do século XXI, as ideologias e as práticas do casamento - e todos os padrões que envolvem a construção psicossocial das identidades masculina e feminina - passaram a ser questionados, gerando uma crise de identidade e de papéis sociais na família e nos padrões de interação conjugal.

As formas e conteúdos do casamento e família que há cerca de duas décadas vêm se difundindo e ganhando legitimidade entre segmentos das classes médias urbanas compartilham muitos dos traços que em diferentes áreas do pensamento, da arte e da cultura conformaram-se com uma tendência pós-moderna. Na literatura, na arquitetura, na arte, no

$\boldsymbol{\nabla} \boldsymbol{\nabla} \boldsymbol{\nabla}$

1 Departamento de Psicologia, Faculdade de Filosofia e Ciências Humanas, Universidade Federal de Minas Gerais. Av. Antônio Carlos, 6627, 31270-901, Belo Horizonte, MG, Brasil. Correspondência para/Correspondence to: O. DINIZ NETO. E-mail: <orestesd@ufmg.br>.

2 Departamento de Psicologia, Pontifícia Universidade Católica do Rio de Janeiro. Rio de Janeiro, RJ, Brasil. 
discurso filosófico. Nas práticas econômicas e políticas, assim como no casamento e na família a heterogeneidade, a pluralidade, a flexibilidade, a instabilidade e a incerteza tornaram-se a regra (Vaitsman, 1994, p.18).

Essa crise psicossocial e institucional da conjugalidade se revela em vários pontos, tais como na diminuição do número de casamentos, oficiais ou não. Os casamentos também estão ocorrendo mais tarde. Nos Estados Unidos, MacGoldrick (1995) ressalta que uma surpreendente porcentagem de 10\% de mulheres está escolhendo não se casar e cerca de 20\% a 30\% dos jovens da presente geração escolheram não ter filhos. Cerca de 75\% dos homens permaneceram ainda solteiros aos 25 anos na década de 1980, contra 55\% da década de 1970.

Observa-se, ainda, o surgimento de alternativas ao modelo tradicional de casamento. Têm ocorrido experiências de novos modelos de relacionamento, desde casamentos informais e abertos, até casamentos comunitários, poligâmicos, poliândricos e, ainda, uniões homossexuais, além de um grande aumento de padrões de experiência extraconjugais (Ferro Bucher, 1999).

Nesse quadro, não surpreende a ocorrência de um aumento do número de divórcios. Nos EUA, em 1962, ocorreram 413 mil divórcios; em 1983, 1179 milhão; e para a década de 1990 considera-se que 50\% dos casamentos terminarão em divórcio (Gottman, 1993). Atualmente, nos EUA, calcula-se que, de cada três casamentos, apenas um permanecerá estável (Goleman, 1998).

No Brasil, as estatísticas indicam que um em cada quatro casamentos terminará em divórcio (Instituto Brasileiro de Geografia e Estatística, 1996). As evidências sugerem que o divórcio se tornou uma variante no ciclo de vida de inúmeras famílias, e que essa tendência permanecerá nos próximos anos (Stern Peck \& Manocherian, 1995).

São diversos os fatores socioculturais envolvidos na mudança dos padrões do casamento contemporâneo, sendo possível, aqui, apenas sumariar alguns, tais como a ampliação do estado de direito e democracia, o movimento de libertação feminino, a abertura do mercado de trabalho à mão-de-obra

134 feminina e a crise pós-moderna.
Cada um desses fatores modificou e foi responsável por reflexos nos padrões psicossociais, resultando em mudanças na estrutura ideológica, sociocultural, econômica e psicológica. Instalou-se assim uma crise dos papéis sociais antes definidos segundo uma ótica capitalista, patriarcal e falocêntrica, possibilitando uma maior mobilidade psicossocial (Ferro-Bucher, 1999).

É possível pensar que, se por um lado a crise indica uma ruptura nos padrões psicossociais, ela também marca a transformação da relação homem e mulher, produzindo novas formas de sujeição e de subjetividades.

\section{A desconstrução da conjugalidade na pós-modernidade}

Mudanças na instituição do casamento não são novas; na crise contemporânea, parece ocorrer uma mudança nos padrões do relacionamento entre indivíduos, com um aumento da mobilidade social, tornando possível que relações insatisfatórias possam ser resolvidas com o rompimento conjugal.

Não parece que a instituição casamento esteja agonizante, mas que estejamos, também, em busca de padrões mais satisfatórios e funcionais de relacionamento amoroso que propiciem condições melhores para o processo de diferenciação e desenvolvimento psicológico e emocional dos parceiros (Bowen, 1978; Goleman, 1998; Féres-Carneiro, 1999; Jablonski, 1999; Féres-Carneiro, 2003; Jablonski, 2003).

Portanto, não se deve pensar a crise da conjugalidade contemporânea como um momento de perda de uma instituição muito bem adaptada e saudável, porém como uma ruptura com padrões psicossociais que trazem consigo normas sociais e familiares disfuncionais, a serviço de uma ideologia dominante (MacGoldrick, 1995).

Na modernidade, a união conjugal tinha um valor precípuo e sua manutenção deveria ser mantida a qualquer preço, conforme a expressão "até que a morte nos separe". As mulheres deveriam se manter fiéis e dedicadas à criação dos filhos, obedecendo aos maridos, em uma repetição de uma relação de submissão social e econômica. A vida pública 
era reduto exclusivo dos homens. Os papéis eram claramente marcados e diferenciados. A desigualdade era aceita e reforçada socialmente, sem qualquer preocupação com os aspectos afetivos e sexuais da mulher.

Jablonski (1999; 2003), por exemplo, tem colocado em relevo o fato de que, mesmo hoje, em nossa cultura, o casamento provoca uma descontinuidade muito profunda na vida das mulheres. Em quase todos os aspectos - físico, mental, e mesmo nas estatísticas criminais-, as mulheres solteiras são mais sadias que as casadas (Apter, 1985). Esses resultados provavelmente se devam aos padrões de dominação que as sociedades e famílias tradicionais impõem às mulheres, reprimindo-as. Além disso, as mulheres demonstram se adaptar melhor e mais rapidamente à situação pós-divórcio que os homens, parecendo indicar que o padrão do divórcio contemporâneo pode ser um evento mais estressante para os homens do que para as mulheres (Gurin, Veroff \& Field, 1980). Féres-Carneiro (2003) ressalta também o mesmo padrão de estresse masculino, notando que pode estar relacionado ao fato de, na maior parte das separações, as mulheres permanecerem em casa com os filhos enquanto os homens se mudam e deixam de acompanhar o cotidiano dos filhos.

Por outro lado, apesar do estereótipo de que o casamento deva ser algo que os homens devam temer e evitar, devido às perdas que ao homem seriam impostas (Jablonski, 2003), muitas pesquisas indicam o contrário, ou seja, que o casamento melhora a saúde física e mental dos homens, estando relacionado, até mesmo, com a melhor possibilidade de sucesso profissional (Gurin, Veroff \& Field, 1980).

Assim, as novas formas de relacionamento que emergem na pós-modernidade podem ser vistas como um movimento libertário contra uma estrutura psicossocial de domínio e exploração, característica das sociedades capitalistas modernas. Portanto, os movimentos sociais característicos da pós-modernidade talvez possam ser mais bem compreendidos como tentativas de resistências e escape aos processos de sujeição, exercidos via biopolítica do poder, como assinalou Foucault (1982), o que não impede que sejam capturados e reutilizados por outras instâncias (Hardt \& Negri, 2002).

\section{A relação conjugal na pós-modernidade}

Uma pergunta se impõe: como se caracterizariam então as relações conjugais na pós-modernidade?

Inicialmente, é preciso caracterizar o que se tem chamado de pós-modernidade. Jameson (1995) nos lembra que, mais do que um período histórico, a pós-modernidade se caracteriza por uma ruptura com a visão moderna de mundo e de homem, uma resposta cultural ao capitalismo tardio, ou às novas formas de dominação nas quais a própria cultura se torna mercadoria de consumo.

[...] assim na cultura pós-moderna, a própria cultura se tornou um produto e o mercado tornou o seu próprio substituto, um produto exatamente igual a qualquer um dos itens que o constituem: o modernismo era, ainda que minimamente e de forma tendencial, uma crítica à mercadoria, um esforço de forçá-la a se autotranscender. O pós-modernismo é o consumo da própria produção de mercadorias como processo (Jamenson, 1995, p.14).

Esse autor destaca como características fundamentais do discurso pós-moderno uma recusa de metanarrativas ou de qualquer projeto metafísico; uma ruptura na temporalidade, com uma contração temporal em uma eterna referência ao discurso presente; uma crítica do representacional; um esmaecimento de fronteiras e limites.

O discurso pós-moderno assume uma tarefa ideológica fundamental: a de coordenar as novas práticas e hábitos sociais e mentais, em novos padrões de organização e de produção econômica, que geram novas formas de subjetividade.

Essas formas de subjetividade são capturadas por forças de produção, ou de agenciamentos, que constituem os novos tipos de dominação e de sujeição a serviço de novas forças de dominação político-econômicas, descritas como capitalismo tardio, com as características próprias (Jameson, 1995). Tais formas de dominação são compostas por uma rede de empresas transnacionais com interesses econômicos que rompem com a política nacionalista e imperialista dos estados modernos, introduzindo uma lógica de produção que rompe com delimitações e fronteiras, características dos estados modernos. Cria-se, assim, nova divisão internacional do trabalho, na qual as 
diferenças das condições de produção são exploradas em uma perspectiva transnacional, rompendo barreiras e divisões tradicionais.

Do ponto de vista econômico, instala-se uma dinâmica vertiginosa de transações bancárias internacionais e de bolsas de valores, que transforma a versão capitalista imperialista em uma instância global de controle financeiro das imensas dívidas do segundo e do terceiro mundo. Instala-se uma nova distribuição de trabalho com a passagem da produção industrial e agrícola para o terceiro mundo, e a concentração da área de serviços no primeiro mundo, criando uma crise das formas de trabalho tradicional pela introdução de diferentes modos de produção e de distribuição do trabalho com alteração nas relações de mais valia. Surgem novas classes sociais, como os yupies, que introduzem novas formas de subjetividade (Jameson, 1995; Hardt \& Negri, 2002). Novas formas de relacionamento de mídias, de transportes, de computadores, de tecnologias de produção e de comunicação introduzem rupturas nas identidades e produzem novas formas de subjetivação (Nicolaci-da-Costa, 2000; 2002).

Jamenson (1995) nos lembra que a relação entre os meios de produção econômico-sociais na pós-modernidade e o cultural não é uma rua de mão única, mas uma interação contínua e recíproca, na qual são produzidas subjetividades específicas através de modos de sujeição que, por sua vez, produzem um campo político, social e cultural em uma atividade retroativa.

O pós-moderno deve ser visto como a produção de pessoas pós-modernas, capazes de funcionar em um mundo socioeconômico muito peculiar, um mundo cujas estruturas, características e demandas objetivas - se dispuséssemos de uma exposição adequada delas - constituiriam a situação para a qual o pós-modernismo é a resposta, e que nos dariam algo mais decisivo do que a teoria do pós-modernismo (Jamenson, 1995, p.18).

A organização sociocultural e econômica reflete-se, portanto, na construção das subjetividades e nas formas de vinculação social, afetiva e sexual, tais como as experimentadas na conjugalidade, que parece estar se caracterizando pela ausência de um modelo único, ou melhor, pela expressão em um modelo de multiplicidade de identidades e papéis que, respondendo a múltiplos contextos, tornam-se contraditórios, levando a novas formas de defesa, como o descompromisso, e uma organização psíquica difusa.

Assim como Lasch (1979) nos fala sobre um culto das relações interpessoais pouco exigentes, Vaitsman (1994) ressalta:"O que caracteriza a família e o casamento numa situação pós-moderna é justamente a inexistência de um modelo dominante, seja no que diz respeito às práticas, seja enquanto um discurso normalizador das práticas" (p.19).

Observamos, então, que as relações de casamento, ainda que norteadas pela busca de satisfação afetiva e sexual, são atingidas pelas forças de sujeição, trazendo sinais de destruição e recriação, pontuadas por resistências às forças de dominação.

Casamentos que insistem em se manter convencionais, na tentativa de repetir um padrão de valores modernos, coexistem com novos estilos de conjugalidade, como manda o padrão mundial de consumo. Outros sujeitos, com suas subjetividades múltiplas submetidas às forças de produção, levam à produção de famílias monoparentais e à crise do par conjugal (Mello da Silveira, 1998).

Podemos observar esses padrões em diferentes aspectos das experiências conjugais: na sexualidade, na afetividade e nas relações familiares, nas quais se experienciam novas identidades pautadas ora nos indivíduos ora no social. A multiplicidade de papéis, com o abandono dos tradicionais, vivenciados em uma rápida sucessão, leva a uma experiência subjetiva de fragmentação. No caso da mulher, além do abandono da posição de "rainha do lar", com a demanda para entrada no mercado de trabalho, a maternidade passou a ser vivida não mais como o aspecto marcante da subjetividade feminina. O papel de mãe e esposa choca-se com o de profissional, levando a uma fusão entre o público e o privado.

No caso do homem, ele perde o lugar de figura de força e poder, esmaecido, primeiro pela autoridade pública, depois pelas mulheres. Encontra-se perdido entre identidades difusas e em mudança. Já não é mais o pai moderno, com quem os filhos têm de disputar o poder, admirando-o e odiando-o, e nem o macho 
dominador, "o cabeça do casal" capaz de fazer o seu desejo prevalecer sobre o da esposa. Perdido, aloja-se em um lugar mais distante nas relações da família.

Os papéis definidos rompem-se, deixando fluidas as fronteiras entre marido e mulher e filhos. Surge a família igualitária. As relações conjugais tornam-se mais instáveis na busca dessa igualdade e da individualidade submetida a campos de multiplicidade contextual. Passam a se sustentar, quase que totalmente, nas satisfações sexual e emocional, que, por sua vez, se tornam instáveis.

Padrões de relação antes vistos como desvios passam a conviver com relações formalizadas, havendo uma heterogeneidade nos relacionamentos afetivosexuais. Não desaparecem os traços do modernismo, surgem outros que convivem com os antigos. Não se acredita mais que duas pessoas sejam feitas uma para a outra. O casamento não é mais para toda a vida. Mas qual é o estatuto da experiência pós-moderna no Brasil?

\section{A conjugalidade no Brasil da pós-modernidade}

A família no Brasil apresenta diferentes padrões de organização ao longo de sua história, desde o modelo patriarcal característico do Brasil colonial até a família nuclear monogâmica, característica da modernidade (Candido, 1951).

Com a Revolução Industrial e as inúmeras mudanças sociais ocorridas a partir do final do século XVIII, os espaços públicos e privados foram demarcados e o mundo público do trabalho passou a ser definido como um mundo masculino. A industrialização crescente no século XIX passou a demandar um número maior de trabalhadores, levando as mulheres, sobretudo aquelas de famílias dos segmentos menos privilegiados da população brasileira, para o trabalho nas fábricas. No início do século $X X$, também as mulheres dos segmentos médios saem dos espaços privados e passam a ocupar cargos de apoio em empresas enquanto se preparam para o casamento (Rocha-Coutinho, 2003). Hoje, apesar da discriminação ainda existente, encontramos as mulheres ocupando posições de destaque no mercado de trabalho, mesmo que na família elas continuem sendo as maiores responsáveis pelas tarefas domésticas e pelos cuidados com os filhos.

Doherty (1992) e Jablonski (2003) ressaltam que, ao longo do século XX, pudemos conviver com três tipos de família. Inicialmente, com a família tradicional, caracterizada pela autoridade paterna, pela produção econômica conjunta, pela ênfase nos aspectos pragmáticos do casamento e por uma composição ampliada que abrigava muitos membros. No momento seguinte, temos a família moderna, muito influenciada pelos valores do individualismo, com uma organização mais nuclear e igualitária, na qual predominam as emoções e os sentimentos. No final do século XX, surge a família pós-moderna, na qual convivem várias formas de arranjos não tradicionais, ainda menos permanentes e mais flexíveis e igualitários que aqueles das famílias da modernidade (Vaitsman, 1994; Goldenberg, 2000; Jablonski, 2003).

Nos últimos anos, na sociedade brasileira, vemos a família sofrer rápidas e profundas mudanças estruturais, tanto na composição de seus membros como na inter-relação de seus papéis. Inúmeras pesquisas têm como objetivo o estudo da família em transformação (Féres-Carneiro, 1999; Jablonski, 1999; Rocha-Coutinho, 2000; Féres-Carneiro, 2003; Jablonski, 2003; Rocha-Coutinho, 2003). Vemos reflexos desse momento de crise com o aumento do número de divórcios e o aumento de famílias monoparentais surgidas sobretudo de separações (Grzybowski, 2002).

Observamos o surgimento de famílias reconstituídas com diferentes estruturas e configurações (Féres-Carneiro, 1999; Jablonski, 1999; Féres-Carneiro, 2003; Jablonski, 2003; Wagner, 2002), bem como os casamentos entre homossexuais (FéresCarneiro, 1997). Nicolaci-da-Costa (2000; 2002) ressalta o surgimento de novas tecnologias como meio de busca e expressão afetivo-sexual, como, por exemplo, o sexo na Internet. Esse quadro marca a crise da identidade masculina e feminina com o surgimento de novos papéis para o homem e para a mulher, em parte pelo aumento da liberdade sexual feminina e da demanda de qualidade nas relações, levando ao aparecimento de novas formas de relação a dois, como o "ficar". Frente a esse quadro, tem ocorrido um aumento do número de homens com disfunções sexuais, perda dos referenciais de papéis parentais 
claramente definidos, e ainda uma sobrecarga das funções da mulher, com acúmulo do papel parental e de provedora (Wagner, 2002).

Esses são sinais do novo campo de construção da subjetividade a que a relação conjugal está submetida. A resposta a essa crise tem se dado por uma multiplicidade de modelos que implicam diferentes papéis, implicitamente incongruentes e conflitantes. O discurso corrente fala de relação amorosa, na qual é preciso preservar o"espaço", garantir a "individualidade" e a "privacidade" dos parceiros. A construção de novas formas e configurações familiares, por outro lado, tem servido de campo para novas formas de subjetivação, na qual os modelos tradicionais de famílias nucleares parecem não oferecer suporte (Féres-Carneiro, 1999; Ferro-Bucher, 1999; Diehl, 2002; Falcke, Diehl \&Wagner, 2002; Wagner, 2002; Féres-Carneiro, 2003). Essa situação convida a uma reflexão sobre a prática da psicoterapia de casal e de família e seu papel na construção da subjetividade na pós-modernidade.

Multifacetado, com uma variedade enorme de funções, sem tempo para perceber-se em cada mudança que acontece, o sujeito da pós-modernidade vê-se fragmentado, mais do que nunca, cindido entre o sentir, o pensar e o agir. Essa diversidade de modelos provoca crises e sintomas, realimentando-se deles.

Nesse contexto, é necessário construir novas abordagens psicoterapêuticas que respondam às demandas dos sujeitos no contexto pós-moderno. Porém, não se pode buscar responder a tais questões com modelos de organizações subjetivas originadas da modernidade e que, presentes nas teorias personalistas e identitárias clássicas da psicoterapia, levam a teorias e discursos centrados na conceituação de identidades construídas em um self auto-referente e monádico.

\section{Rupturas na epistemologia do "si-mesmo": novas possibilidades terapêuticas}

O que comumente se chama de crise da pós-modernidade é, na verdade, um processo de superação da visão de homem e de mundo característico do período moderno, com o aparecimento de novas propostas epistemológicas e estéticas.
A modernidade leva-nos a construir uma certa visão de mundo caracterizada pelas grandes metanarrativas: discursos totalizadores que trazem em seu bojo pressupostos tanto de uma posição metafísica da essencialidade, como de uma posição epistemológica da possibilidade de um conhecimento verdadeiro, pretendendo, assim, uma posição de ordenador do pensamento e de outros discursos.

$\mathrm{Na}$ tentativa de construir uma psicologia científica moderna, a questão "o que é o self?" parece central. Seu núcleo é, ao mesmo tempo, uma pergunta metafísica e epistemológica. No sentido epistemológico, o self pode ser conhecido não só pelo próprio como pelos demais. Em conseqüência, pode ser observado, medido, avaliado, quantificado. De qualquer modo que se entenda a pergunta, ela pressupõe a existência de uma entidade que pré-exista à nossa necessidade de descrevê-la. No sentido metafísico, perguntar o que é o self significa perguntar sobre a essência daquilo que se interroga, implicando em algo central, inerente à condição humana e irredutível.

Todas as abordagens tradicionais na psicologia, subjetivistas e essencialistas, concebem que o self é delimitado. Há o self e o "não self". Cada pessoa seria um acontecimento único, em um universo delimitado e integrado, e o centro de suas ações. Essa posição convida a certas perguntas, tais como: de que somos conscientes quando somos conscientes de nós mesmos? Como saber se nossa consciência reflete o estado real de nossa mente? Que é este self e como podemos verdadeiramente conhecê-lo?

Perguntas como essas criaram muitos dilemas, aos quais Descartes, por exemplo, respondeu definindo uma divisão metafísica da realidade, do sujeito e do objeto, em termos de uma "res extensa" e "res cogitans".

A Psicologia Cognitiva tem evitado a cisão cartesiana e essas questões, afirmando a emergência quer do self quer da consciência como explicável pelas ações do sistema nervoso central. A metáfora é computacional: segundo esse modelo computadorizado e cognitivo do sistema psicológico, as operações mentais e do self só processam informações e resultados em relação a um critério ou sintaxe intrínsecos, construídos dentro do sistema. 
Sob essa acepção encontra-se muito da chamada revolução cognitiva. Esses pontos de vista se apoiam na idéia cartesiana e lokeana de que a mente é um espaço fechado e auto-suficiente. O perigo dessa crença epistemológica modernista consiste em supor que é possível reduzir todos os fenômenos psíquicos a alguma base ou modelo último, a alguma origem fundamental, e é por isso que todas têm uma explicação de base causal essencialista, que remete a algum tipo de fundamento imanente.

A posição pós-moderna não rejeita o discurso e as teorias modernas sobre o self por assumir outro fundamento, mas por relativizar todo os discursos. Ela aponta para a impossibilidade de uma fundamentação imanente, e assume a relatividade dos discursos como paradigmática, abrindo outros caminhos que, por exemplo, nos permitem evitar a posição da existência transcendental de um self, tornando desnecessária uma concepção epistemológica e metafísica do si-mesmo. Isso nos situa no campo pós-moderno e nas atividades da hermenêutica e da interpretação.

No processo de valorização da exploração da multiplicidade dos discursos, o"eu", o ego, o self, os papéis sociais e as identificações deixam de ser expressões da neurofisiologia e não podem ser explicáveis por um discurso fundacional.

Muitos cientistas sociais, há mais de vinte anos, começam a explorar as conseqüências de definir o self como narrador e como um processo humano produtor de significados por meio da ação da linguagem. O self pode ser, em uma perspectiva pós-moderna, considerado como uma expressão dessa capacidade para a linguagem e a narrativa, que são atos sociais. $\mathrm{Na}$ melhor das hipóteses, não somos mais que co-autores de uma narrativa em permanente mudança, que se transforma em nosso "si-mesmo". Histórias imersas no nosso passado, narradas em função de um futuro contado em múltiplos contextos.

Essa perspectiva não é nova. Freud (1968), na sua obra "Construções na análise", de 1936, aponta que quando a análise das defesas do "eu" e o processo de associação livre não recuperam as necessárias lembranças edípicas da infância, é possível para o analista criar uma história próxima do que o paciente poderia ter recordado. Assim, Freud rechaça a abordagem narrativa ao compará-la com a idéia delirante do psicótico, alertando-nos sobre os riscos dessa possível "intervenção" por parte do analista.

Spence (1984) estendeu o conceito para uma abordagem narrativa e construtivista. Segundo ele, já que nunca podemos chegar à verdade real das vivências infantis, temos que nos contentar com um relato construído, que seja adequado ao cliente e às circunstâncias. Segundo esse ponto de vista, a tarefa da psicoterapia parece consistir na construção de uma história de vida que seja consistente com as circunstâncias atuais do paciente, sem levar em conta a verdade "arqueológica" dessa construção.

Schafer (1978) adota uma perspectiva mais próxima de Wittgenstein e do construtivismo social. Para ele, o selfé uma manifestação da ação humana, da ação de falar sobre o si mesmo. No entanto, diferentemente de Spence (1984), que estava interessado no conteúdo da narrativa, Shafer (1978) interessa-se pelo modo da construção e pelo discurso narrativo. Ele sustenta que estamos contando, aparentemente, a nós mesmos e aos outros, quem somos, incorporando essas histórias umas às outras. Dessa perspectiva, o"si-mesmo" se converte nas maneiras mais ou menos estáveis e emocionais de contar, a nós mesmos e aos outros, sobre nossa continuidade no processo de viver, em nosso enlaçamento, e os significados de nossas interações.

Para Shafer (1978), assim como para outros psicoterapeutas pós-modernos, também o outro se manifesta narrativamente. $O$ desafio terapêutico, nessa perspectiva, consiste em auxiliar os clientes a recontar as histórias de suas vidas de maneira que Ihes permita uma compreensão de sua origem, de seu significado e de suas atuais dificuldades, de tal forma que a mudança se torne narrativamente concebível, alcançável e crível.

Como assinala Rorty (1979), os seres humanos são geradores perpétuos de novas descrições e narrações, mais do que seres que se possam descrever de maneira precisa, objetiva e fixa. Isso faz com que a natureza do self e a de nossas subjetividades se convertam em fenômenos intersubjetivos. Tais fenômenos são o produto de narrarmos histórias uns aos outros e a nós mesmos, acerca de nós e dos outros, 
e das histórias que outros narram para nós, sobre nós e sobre eles.

A cambiante rede de narrativas é produto de intercâmbio e práticas sociais, do diálogo e da conversação.

Para esta visão pós-moderna não somos mais que co-autores das identidades que construímos narrativamente. Somos sempre tanto si mesmos potenciais quanto aqueles que estão contidos nas conversações dos narradores (Goolishian \& Anderson, 1996, p.195).

Do ponto de vista da psicoterapia de casal, essas colocações nos afastam de uma determinada visão da terapia de família que vê os sistemas como uma arquitetura social relativamente fixa, e convida-nos a vê-los como um sistema intersubjetivo, fluido de construção de significados.

Para a abordagem narrativa, a psicoterapia é um processo conversacional. Na psicoterapia, o objetivo passa a ser a narrativa de uma nova história, de um novo presente que seja mais tolerável, coerente e contínuo, do que aqueles que as narrativas anteriores permitiam.

A mudança passa a centrar-se mais no nosso ser e devir que em um passado histórico cambiante. Em psicoterapia, esse é o resultado de mudar as autonarrativas do self, e tem como conseqüência uma transformação do agente e da interação, ou seja, do self e do contexto. Portanto, uma questão emerge: que narrativas construir?

Uma psicoterapia imbuída de uma tradição hermenêutica implica a abertura a novos significados, o abandono de uma metanarrativa paradigmática supra-ordenadora de sentidos. Saber de antemão, seja a partir de uma teoria ou de um diagnóstico, é reduzir a compreensão a um nível tão abstrato que passa por cima da índole intersubjetiva, única e singular da interpretação naquela interação e contexto.

Toda ação social pode ser concebida como o resultado de uma interação em um sistema de indivíduos que atuam, ajustando e conectando seus comportamentos, em relação a si mesmos e aos demais, mediante um processo hermenêutico de interpretação de si mesmos, ou seja, através da

140 construção da narrativa humana.
Vivemos, uns com os outros, vidas narradas. A pressão social - o estigma do divórcio, o fato de a mulher depender economicamente do marido etc. -, que antes mantinha os casais unidos, não é mais o "alicerce" do casamento. Novas narrativas serão necessárias para a construção das novas formas de conjugalidade.

Temos aí, então, um bom motivo para acreditar, como Goleman (1998), que são as forças dos sentimentos que determinam a sobrevivência do laço conjugal. Como psicoterapeutas de casal, essa crença deve permear nossa prática diária, não podendo deixar de estar presente na nossa intenção e na nossa compreensão.

\section{Referências}

Apter, T. (1985). Why women don't have wifes? New York: Schocken.

Bowen, M. (1978). Family therapy and clinical practice. New York: Jason Aronson.

Candido, A. (1951). The brazilian family. In A. Hartman (Org.). Brazil: Portrait of development (pp. 291-312). New York: The Dryden Press.

Diehl, A. (2002). O homem e a nova mulher: novos padrões sexuais de conjugalidade. In A. Wagner (Org.). Família em cena (pp.135-158). Petrópolis: Vozes.

Doherty, W.J. (1992). Private lives, public values. Psychology Today, Mai/June, 32-37.

Falcke, D., Diehl, J.A., \& Wagner, A. (2002). Satisfação conjugal na atualidade. In A. Wagner (Org.). Família em cena (p.172188). Petrópolis: Vozes.

Féres-Carneiro, T. (1997). Escolha amorosa e interação conjugal na hetero e na homossexualidade. Psicologia: Reflexão e Crítica, 10 (2), 351-368.

Féres-Carneiro, T. (1999). Conjugalidade: um estudo sobre as diferentes dimensões da relação amorosa heterossexual e homossexual. In T. Féres-Carneiro (Org.). Casal e família: entre a tradição e a transformação (pp. 96-117). Rio de Janeiro: Nau Editora.

Féres-Carneiro, T. (2003). Construção e dissolução do laço conjugal na terapia de casal. In T. Féres-Carneiro (Org.). Família e casal: arranjos e demandas contemporâneas (pp. 201-214). Rio de Janeiro: PUC-Rio.

Ferro-Bucher, J.S.N. (1999). O casal e família sob novas formas de interação. In T. Féres-Carneiro (Org.). Casal e família: entre a tradição e a transformação (pp.169-193). Rio de Janeiro: Nau Editora.

Foucault, M. (1982). Hermeneutique du sujet. Paris: Seuil/ Gallimard.

Freud, S. (1968). Construcciones en psicoanalisis. In Obras completas. Vol. III. Madri: Editorial Nueva Madri. 
Goldenberg, M. (2000). De Amélias a operárias: um ensaio sobre os conflitos femininos no mercado de trabalho e nas relações conjugais. In M. Goldenberg (Org.). Os novos desejos (pp.105-124). Rio de Janeiro: Record.

Goleman, D. (1998). A Inteligência emocional. Rio de Janeiro: Objetiva.

Goolishian, H.A., \& Anderson, H. (1996). Narrativa e self: alguns dilemas pós-modernos da psicoterapia. In D.F. Schnitman (Org.). Novos paradigmas, cultura e subjetividade (pp.191-200). Porto Alegre: Artes Médicas.

Gottman, J.M. (1993). What predicts divorce: relations between marital process and marital outcome. Hillsdale: Lawrence Erilbaun Associates.

Grzybowski, L.S. (2002). Famílias monoparentais: mulheres divorciadas chefes de família. In A. Wagner (Org.). Família em cena (pp.39-53). Petrópolis: Vozes.

Gurin, G., Veroff, J., \& Field, S. (1980). Americans view their health. New York: Basic Books.

Hardt, M., \& Negri, A. (2002). Império. Rio de Janeiro: Record.

Instituto Brasileiro de Geografia e Estatística (1996). Pesquisa nacional por amostra de domicílios. Rio de Janeiro.

Jablonski, B. (1999). Identidade masculina e paternidade: de onde vimos e para onde vamos. In T. Féres-Carneiro (Org.). Casal e família: entre a tradição e a transformação (pp.55-69). Rio de Janeiro: Editora Nau.

Jablonski, B. (2003). Afinal o que quer um casal? Algumas considerações sobre o casamento e a separação na classe média carioca. In T. Féres-Carneiro (Org.). Família e casal: arranjos e demandas contemporâneas (pp. 141-168). Rio de Janeiro: PUC-Rio.

Jameson, F. (1995). Pós-modernismo. Rio de Janeiro: Ática.

Lasch, C. (1979). Refúgio num mundo sem coração; a família: santuário ou instituição sitiada? Rio de Janeiro: Paz e Terra.

MacGoldrick, M. (1995). A união das famílias através do casamento: o novo casal. In B. Carter \& M. MacGoldrick. As mudanças no ciclo de vida familiar (pp.184-205). Porto Alegre: Artes Médicas.
Mello da Silveira, T. (1998). A construção criativa na vida do casal: limites e possibilidades do casamento contemporâneo. Dissertação de mestrado, Pontifícia Universidade Católica do Rio de Janeiro.

Nicolaci-da-Costa, A.M. (2000). Nas malhas da rede: os impactos íntimos da Internet. Rio de Janeiro: Campus.

Nicolaci-da-Costa, A.M. (2002). Estamos diante de uma nova revolução tecnológica? Projeto de pesquisa, Departamento de Psicologia, Pontifícia Universidade Católica do Rio de Janeiro.

Rocha-Coutinho, M.L. (2000). Dos contos de fada aos superheróis: mulheres e homens brasileiros reconfiguram identidades. Psicologia Clínica, 2 (12), 65-82.

Rocha-Coutinho, M.L. (2003). Quando o executivo é uma dama. In T. Féres-Carneiro (Org.). Família e casal: arranjos e demandas contemporâneas (pp.57-77). Rio de Janeiro: PUC-Rio.

Rorty, R. (1979). Philosophy and the mirror of nature. Princeton: Princenton University Press.

Schafer, R. (1978). Language and insight. New Haven: Yale University Press.

Spence, D. (1984). Narrative truth and historical truth: meaning and interpretations in psychoanalysis. New York: Norton.

Stern Peck, J., \& Manocherian, J. (1995). O divórcio no ciclo de vida familiar. In B. Carter \&M. MacGoldrick. As mudanças no ciclo de vida familiar (pp. 291-320). Porto Alegre: Artes Médicas.

Vaitsman, J. (1994). Flexíveis e plurais: identidade, casamento, e família em circunstâncias pós-modernas. Rio de Janeiro: Rocco.

Wagner, A. (2002). Possibilidades e potencialidade da família: a construção de novos arranjos a partir do recasamento. In A. Wagner (Org.). Família em cena (pp.23-28). Petrópolis: Vozes.

Recebido para publicação em 27 de novembro de 2003 e aceito em 1 de março de 2005. 
